\title{
Poly(L-lactic acid) Modified by Magnesium Phenylmalonate: Thermal Behavior, Processing Fluidity, and Mechanical Properties
}

\author{
Liangliang TIAN, Yanhua CAI*
}

Chongqing Key Laboratory of Environmental Materials \& Remediation Technologies, Chongqing University of Arts
and Sciences, Chongqing-402160, P.R. China

cross ref http://dx.doi.org/10.5755/j01.ms.24.1.17947

Received 12 April 2017; accepted 22 May 2017

\begin{abstract}
This study presents the role of the magnesium phenylmalonate (MgPA) in the thermal behavior, fluidity, and mechanical properties of Poly(L-lactic acid) (PLLA). The results from non-isothermal crystallization investigation showed that the presence of MgPA as a heterogeneous nucleating agent facilitated the crystallization of PLLA in cooling. Additionally, the non-isothermal crystallization behavior of PLLA/MgPA was affected significantly by MgPA concentration, the cooling rate, and the final melting temperature. Melting behavior of PLLA/MgPA under different testing conditions further confirmed the crystallization accelerating effect of MgPA for PLLA, and the double melting peaks of PLLA/MgPA system mainly assigned to the melting-recrystallization mechanism. A decrease of the onset decomposition temperature indicated that the incorporation of MgPA reduced the thermal stability of PLLA, but the effect of MgPA on the thermal decomposition profile of PLLA is negligible. Compared to the primary PLLA, the addition of MgPA could improve significantly the fluidity of the PLLA, and the fluidity became better with increasing of $\mathrm{MgPA}$ concentration in PLLA matrix. MgPA of $0.2 \mathrm{wt} \%$ to $2 \mathrm{wt} \%$ could make the tensile strength of PLLA increase, however, a continuous drop in elongation at break was also observed.

Keywords: poly(L-lactic acid), magnesium phenylmalonate, non-isothermal crystallization, fluidity, mechanical properties.
\end{abstract}

\section{INTRODUCTION}

Now, environmental pollution has becoming the global problem, thus, the face of growing white pollution, developing environment-friendly plastics in polymer field is very urgent and necessary to protect the global ecological environment. Poly(L-lactic acid) (PLLA), as one of the most important biodegradable polymers, has achieved the large-scale production through a lot of sustained hard work of multinationals such as Nature Works LLC, Mitsui Chemicals Group, etc. And PLLA also represents clearly an alternative to petroleum-based polymers in food packaging [1,2], disposable tableware [3], and mulch films [4] because of its biodegradability, nontoxic, good biocompatibility [5, 6]. For example, nisinloaded chitosan/PLLA antimicrobial films were fabricated via coating method, and the results from diffusion behavior and antimicrobial activity of nisin-loaded chitosan/PLLA films revealed well-controlled release and antimicrobial activity against Staphylococcus aureus ATCC6538, showing that nisin-loaded chitosan/PLLA films may be a promising active food packaging film [7].

However, some major defects including the slow crystallization rate, poor heat resistance, and low melt strength, etc., restrict seriously the application of PLLA in more industry fields, the most effective and simple way to improve the aforementioned defects is the introduction of functional additives in PLLA matrix. Aiming at the slow crystallization rate of PLLA, many nucleating agents, including talc [8], carbon black [9], dilithium

\footnotetext{
${ }^{*}$ Corresponding author. Tel.: +86-23-61162815; fax: +86-23-61162725

E-mail address: caiyh651@aliyun.com (Y.H. Cai)
}

hexahydrophthalate [10], phthalhydrazide [11], $\mathrm{N}$-aminophthalimide [12], etc., were introduced into PLLA matrix to accelerate the crystallization process. For instance, benzoyl hydrazine derivatives with different structures were designed and synthesized to act as nucleating agents for PLLA, and the crystallization behavior confirmed that benzoyl hydrazine derivatives had a remarkable promoting effect for PLLA crystallization [13-15]. In particular, the addition of $0.8 \mathrm{wt} \% \mathrm{~N}, \mathrm{~N}$ 'Bis(benzoyl) suberic acid dihydrazide could cause the crystallization half-time of the PLLA to decrease from 26.5

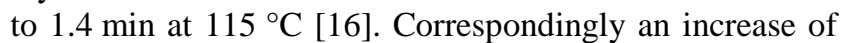
crystallinity must lead to the higher heat distortion temperature and enhancement of heat resistance. Overcoming the low melt strength of PLLA, introducing long branched chains was proved to be effective method to improve the melt strength [17]. Thus, Yang and his team synthesized firstly microcrystalline cellulose-graftpolylactic acid copolymer via melt copolycondensation, and then investigate the effect of microcrystalline cellulose-graft-polylactic acid copolymer on the melt strength of PLLA. The elongational viscosity increased with increasing concentration of microcrystalline cellulosegraft-polylactic acid copolymer in PLA matrix, suggesting that the addition of microcrystalline cellulose-graftpolylactic acid copolymer enhanced the melt strength of PLLA [18].

Salts of phenylmalonic acid, as one of the most important organic metallic salts, exhibit the excellent compatibility with polymer because of its organic section, and the stable structure stemming from its inorganic section, and these advantages have contributed to the use of salts of phenylmalonic acid as efficient functional 
additives in polymer resin. Thus, salts of phenylmalonic acid including lithium phenylmalonate, calcium phenylmalonate, strontium phenylmalonate, barium phenylmalonate, cadmium phenylmalonate, zinc phenylmalonate, etc., were added to PLLA matrix to investigate their influences on crystallization performances of PLLA [19], it was found that, apart from potassium phenylmalonate, other salts of phenylmalonic acid could serve as nucleating agents for the crystallization of PLLA. However, their work only focused on the comparative study of different salts of phenylmalonic acid for the crystallization of PLLA, the effects of a certain salt of phenylmalonic acid on thermal performances, processing fluidity, and mechanical properties of PLLA were not reported, these studies is very necessary to further reveal the role of MgPA in PLLA matrix. Thus, in this investigation, we mainly focus on the non-isothermal crystallization behavior, melting behavior under different conditions, thermal stability, melt index, and mechanical properties of magnesium phenylmalonate (designated as MgPA) nucleated PLLA through differential scanning calorimeter (DSC), thermogravimetric analysis (TGA), melt index instrument, and electronic tensioner.

\section{EXPERIMENTAL}

\subsection{Materials}

2002D PLLA (the D content $4.25 \%$, the $\mathrm{M}_{\mathrm{w}} 1.9 \times 10^{5}$ ) was obtained from Nature Works LLC, USA. The magnesium phenylmalonate was synthesized in our laboratory according to the literature [19].

\subsection{Preparation of PLLA/MgPA}

The PLLA and MgPA were mixed in the beaker, and dried for $24 \mathrm{~h}$ at $45^{\circ} \mathrm{C}$ in a vacuum oven. Melting process of the PLLA and MgPA mixture was performed on RM-200C torque rheometer with a rotation speed of $32 \mathrm{rpm}$ for $7 \mathrm{~min}$, then at $64 \mathrm{rpm}$ for $7 \mathrm{~min}$ at $190{ }^{\circ} \mathrm{C}$. And then the resulting mixture was hot pressed in a mould with a $0.4 \mathrm{~mm}$ thickness for $5 \mathrm{~min}$ at $190^{\circ} \mathrm{C}$, and cool pressed at room temperature for $10 \mathrm{~min}$ to obtain the PLLA with different concentration MgPA samples.

\subsection{Testing}

The non-isothermal crystallization and melting behavior of the primary PLLA and PLLA/MgPA samples were tested using TA Instruments Q2000 DSC with $50 \mathrm{~mL} / \mathrm{min}$ nitrogen. The thermal stability from room temperature to $650{ }^{\circ} \mathrm{C}$ was determined by TA Instruments Q500 TGA, and the airflow rate and the heating rate were $60 \mathrm{~mL} / \mathrm{min}$ and $5{ }^{\circ} \mathrm{C} / \mathrm{min}$, respectively. The fluidity was measured by the melt index instrument (Beijing Guance Testing Instrument Co., LTD, China), and the relevant testing parameters were following: the testing temperature $190{ }^{\circ} \mathrm{C}$, load $2.16 \mathrm{~kg}$. The testing specimens of mechanical properties were prepared through pneumatic sheetpunching machine, and the tensile tests were conducted on a D\&G DX-10000 electronic tensile tester at the speed of $50 \mathrm{~mm} / \mathrm{min}$ at room temperature, and the relevant mechanical properties data including tensile strength and elongations at break were obtained by averaging over four specimens.

\section{RESULTS AND DISCUSSION}

\subsection{Non-isothermal crystallization behavior}

Slow crystallization rate is one of the worst problem during processing, thus, the effect of MgPA on nonisothermal crystallization of PLLA was investigated firstly. Fig. 1 presents the DSC curves of non-isothermal crystallization of the primary PLLA and PLLA/MgPA samples from $190{ }^{\circ} \mathrm{C}$ at a cooling rate of $1{ }^{\circ} \mathrm{C} / \mathrm{min}$. Through DSC curves analysis, it is very clear that the primary PLLA does almost not have non-isothermal crystallization peak in cooling, showing that the crystallization ability of the primary PLLA itself is very poor as reported by other literatures [20, 21]. In contrast, the addition of MgPA exhibits completely different results, that is, all PLLA/MgPA samples have obvious nonisothermal crystallization peaks in DSC cooling curves, indicating that the MgPA promotes the crystallization of PLLA. Additionally, the influence of MgPA concentration on non-isothermal crystallization behavior of PLLA is also observed from Fig. 1. At the range of MgPA concentrations, the non-isothermal crystallization of PLLA can be classified into two stages. When MgPA concentration is $0.2 \mathrm{wt} . \%$ to $1 \mathrm{wt} . \%$, the onset crystallization temperature and the crystallization peak temperature do almost not depend on the MgPA concentration, but PLLA/0.5\%MgPA sample has the sharpest non-isothermal crystallization peak, indicating that it has the largest crystallization rate in cooling. Compared to the primary PLLA, $0.5 \mathrm{wt} \%$ MgPA causes the onset crystallization temperature, the crystallization peak temperature and the non-isothermal crystallization enthalpy of PLLA to give rise to an increase from $101.4^{\circ} \mathrm{C}, 94.5^{\circ} \mathrm{C}$, and $0.1 \mathrm{~J} / \mathrm{g}$ to $119.2^{\circ} \mathrm{C}, 113.8^{\circ} \mathrm{C}$, $34.5 \mathrm{~J} / \mathrm{g}$, respectively. After the non-isothermal crystallization process, the degree of crystallinity increases from $0.1 \%$ to $37.0 \%$ (Here, the degree of crystallinity of the primary PLLA and PLLA/MgPA system was calculated according to the literature [22]).

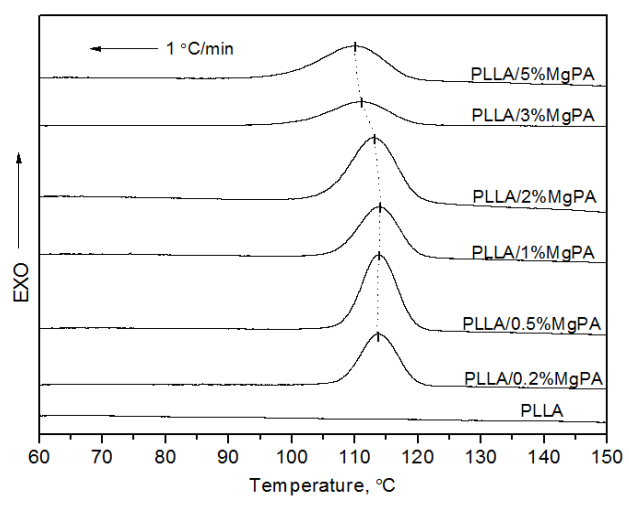

Fig. 1. DSC curves of non-isothermal crystallization of the primary PLLA and PLLA/MgPA from $190{ }^{\circ} \mathrm{C}$ at a cooling rate of $1^{\circ} \mathrm{C} / \mathrm{min}$

When MgPA concentration is $2 \mathrm{wt}$.\% to $5 \mathrm{wt} . \%$, with an increase of MgPA concentration, the non-isothermal 
crystallization peak shifts to lower temperature, indicating that its crystallization process starts at a lower temperature. Moreover, the non-isothermal crystallization peak also becomes much wider, resulting from the impediment effect of excessive MgPA for PLLA crystallization. Aforementioned non-isothermal crystallization results, 0.5 wt. \% MgPA exhibits the best crystallization accelerating effect for PLLA. To further reveal the role of MgPA in PLLA matrix, a comparative study of nonisothermal crystallization process from the melt and room temperature was performed. Fig. 2 presents the DSC curves of non-isothermal crystallization of PLLA/0.5\% MgPA from the melt crystallization and cooling crystallization. The temperature of the nonisothermal crystallization peak from melt crystallization is higher than that from cooling crystallization, and the nonisothermal crystallization enthalpy is also larger, the reason is that the MgPA as a heterogeneous nucleating agent can make the PLLA nucleate rapidly, and excellent motility of PLLA molecular segment in high temperature regions promotes PLLA to form rapidly crystal during cooling from the melt. Whereas poor motility results in the decrease of crystal number during heating from room temperature, although that the nuclear rate is faster because of heterogeneous nucleation of $\mathrm{MgPA}$ and homogeneous nucleation of PLLA itself in low temperature regions, suggesting that, upon the existence of nucleating agent $\mathrm{MgPA}$, the crystallization of PLLA mainly depends on the motility of molecular chains.

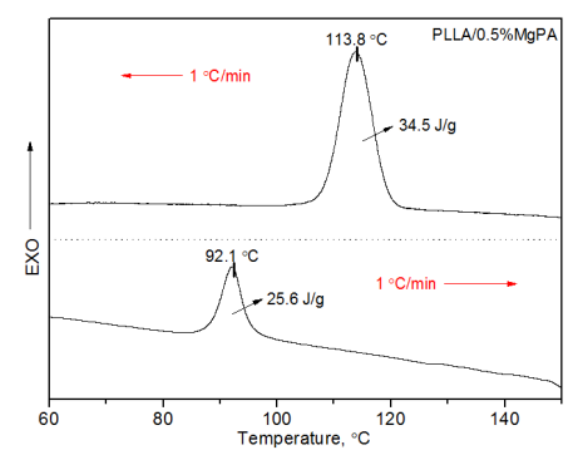

Fig. 2. DSC curves of non-isothermal crystallization of PLLA $/ 0.5 \% \mathrm{MgPA}$ at a rate of $1{ }^{\circ} \mathrm{C} / \mathrm{min}$ from the melt crystallization and cooling crystallization

Apart from the additives concentration, the cooling rate often affects the non-isothermal crystallization behavior of polymers [23]. Fig. 3 shows the DSC curves of nonisothermal crystallization behavior of PLLA/MgPA samples from the melt at a cooling rate of $2{ }^{\circ} \mathrm{C} / \mathrm{min}$. Compared to the cooling rate of $1^{\circ} \mathrm{C} / \mathrm{min}$, an increase of cooling rate leads to the shift of crystallization peak to lower temperature and wider crystallization peaks, meaning a decrease of crystallization ability of PLLA/MgPA sample, confirming that the competitive relationship of cooling rate and $\mathrm{MgPA}$ for promoting crystallization of PLLA, that is, the crystallization of PLLA/MgPA sample is suppressed by a high cooling rate. On the other hand, under the same cooling rate, it is observed that the non-isothermal crystallization behavior of PLLA/MgPA samples depends on not only MgPA concentration but also a specific cooling rate, which indicates complexity of crystallization of PLLA/MgPA samples under this circumstance.



Fig. 3. DSC curves of non-isothermal crystallization of PLLA/MgPA samples from the melt at a rate of $2{ }^{\circ} \mathrm{C} / \mathrm{min}$

In addition, the final melting temperature is also another important factor to non-isothermal crystallization of polymers [24, 25], especially for the additive with organic and inorganic section, resulting from the different solubility of the additive in polymer matrix at different melting temperature, whereas the solubility would affect directly the nucleating density and compatibility. Fig. 4 displays the non-isothermal crystallization DSC curves of PLLA/MgPA samples from the different final melting temperatures at a cooling rate of $1{ }^{\circ} \mathrm{C} / \mathrm{min}$.
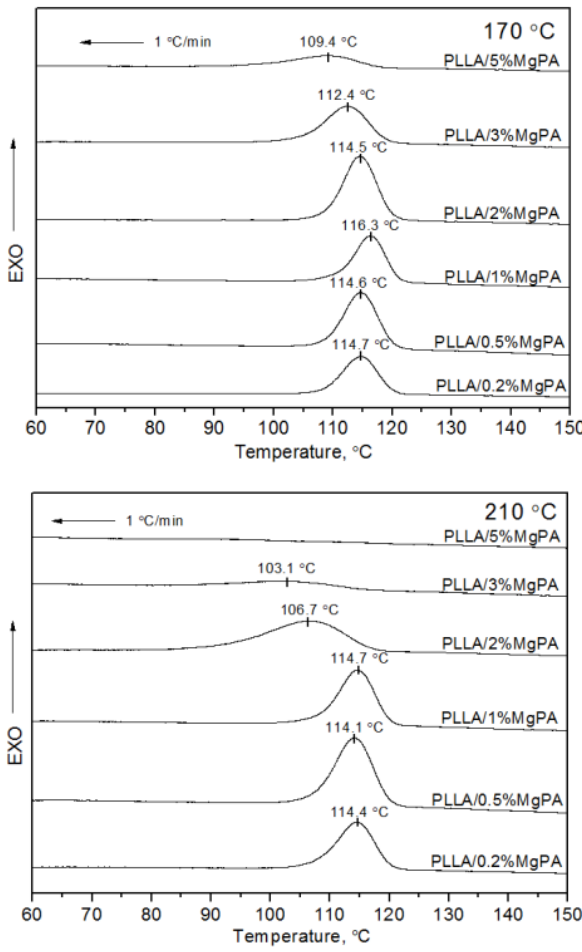

Fig. 4. Non-isothermal crystallization DSC curves of PLLA/MgPA from the different final melting temperature at a cooling rate of $1{ }^{\circ} \mathrm{C} / \mathrm{min}$

As shown in Fig. 4, when the final melting temperature is $170{ }^{\circ} \mathrm{C}$, the temperature of the nonisothermal crystallization peak of PLLA/MgPA sample, in comparison to the final melting temperature of $210^{\circ} \mathrm{C}$, is higher, showing higher crystallization temperature and more powerful crystallization ability. The probable reason is that more organic section of MgPA is dissolved in PLLA 
matrix at higher melting temperature, resulting in the enhancement of compatibility between PLLA and MgPA. However, at the same time, that results in poor stability of $\mathrm{MgPA}$ as a heterogeneous nucleating agent and subsequent crystallization promoting effect of MgPA for PLLA in cooling. Moreover, the difference of non-isothermal crystallization peak temperature of the same PLLA/MgPA sample at the final melting temperature of $170{ }^{\circ} \mathrm{C}$ and $210{ }^{\circ} \mathrm{C}$ increases with increasing of MgPA concentration, which further confirms aforementioned relationship between the solubility, stability, and crystallization ability.

\subsection{Melting behavior}

In non-isothermal crystallization section, the temperature of the maximum crystallization rate of PLLA/0.5\% MgPA appears at nearby $115^{\circ} \mathrm{C}$. Thus, we choose $115^{\circ} \mathrm{C}$ as the isothermal crystallization temperature to investigate the melting behavior of PLLA/ $0.5 \% \mathrm{MgPA}$ after isothermal crystallization. The melting behavior of PLLA/MgPA at a heating rate of $10^{\circ} \mathrm{C} / \mathrm{min}$ after isothermal crystallization at $115^{\circ} \mathrm{C}$ for different time was shown in Fig. 5. It is clear that, with increasing of crystallization time, the low-temperature melting peak shifts to higher temperature, and the high-temperature melting peak degenerates gradually to merge into a single peak with low-temperature melting peak. When the crystallization time increases from $30 \mathrm{~min}$ to $300 \mathrm{~min}$, more crystals were formed in the presence of MgPA, resulting in more difficult in reforming the crystal during heating because of the decrease of MgPA as effective crystal nucleus. This result evidences that the melting mechanism of PLLA/MgPA system assigns to meltingrecrystallization. Furthermore, the almost identical temperatures of all high-temperature melting peaks also further confirm the melting-recrystallization [26].

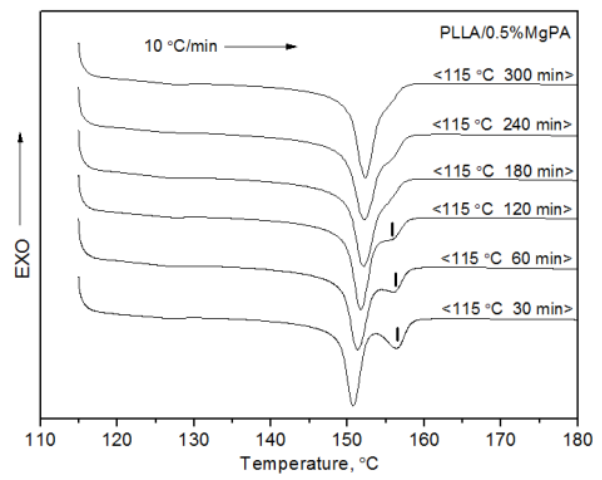

Fig. 5. Melting behavior of PLLA/MgPA at a heating rate of $10{ }^{\circ} \mathrm{C} / \mathrm{min}$ after isothermal crystallization at $115^{\circ} \mathrm{C}$ for different time

For melting behaviors after isothermal crystallization, crystallization temperature can significantly affect the melting behavior. Fig. 6 shows the melting behavior of PLLA/ $0.5 \% \mathrm{MgPA}$ at a heating rate of $10^{\circ} \mathrm{C} / \mathrm{min}$ after isothermal crystallization at different temperature for 180 min. As seen in Fig. 6, insufficient crystallization occurs in low temperature region from $95^{\circ} \mathrm{C}$ to $105^{\circ} \mathrm{C}$, which may result in the appearance of polymorphism of crystals, and the co-action of polymorphism and meltingrecrystallization lead to the appearance of double melting peaks. In contrast, these exists only a single peak in high temperature region from $125^{\circ} \mathrm{C}$ to $135^{\circ} \mathrm{C}$. Moreover, the melting peak shifts toward the higher temperature. However, it is also noted that the melting peak after isothermal crystallization at $135^{\circ} \mathrm{C}$, in comparison to the melting peak after isothermal crystallization at $125^{\circ} \mathrm{C}$, become wider, indicating that crystal perfection becomes poor resulting from the stronger motility of PLLA molecular segment in higher temperature region and corresponding disorderly arrangement. This result also further demonstrates the crystallization temperature is crucial for PLLA isothermal crystallization in the presence of nucleating agent MgPA.



Fig. 6. Melting behavior of PLLA/ $0.5 \% \mathrm{MgPA}$ at a heating rate of $10{ }^{\circ} \mathrm{C} / \mathrm{min}$ after isothermal crystallization at different temperature for $180 \mathrm{~min}$

In non-isothermal crystallization section, the cooling rate exhibits significant influence on the non-isothermal crystallization behavior of PLLA/MgPA samples. Similarly, the heating rate must be an important influence factor for the melting behavior of PLLA/MgPA. Fig. 7 shows the melting behavior of PLLA/0.5\% MgPA sample at different heating rates after non-isothermal crystallization (cooling rate $1^{\circ} \mathrm{C} / \mathrm{min}$ ).

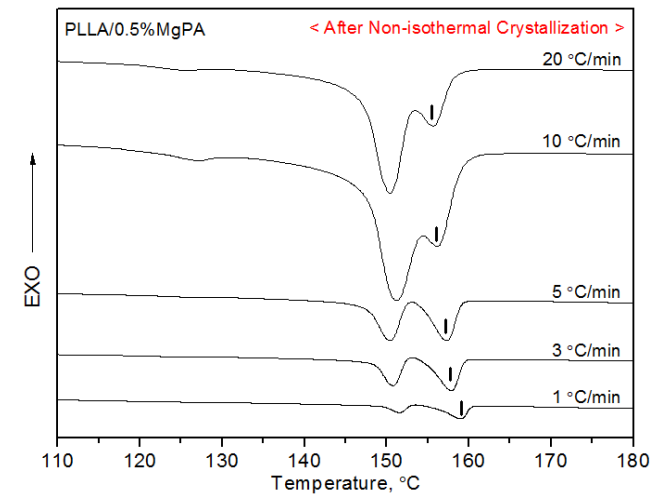

Fig. 7. Melting behavior of PLLA/0.5\%MgPA at different heating rates after non-isothermal crystallization

With increasing of the heating rate, the hightemperature melting peak shifts to lower temperature, and the peak area also decreases compared with the lowtemperature melting peak, the reason is still that an increase of heating rate makes the crystal number decrease and perfection become poor. Whereas because the perfections of these crystals formed in cooling are uniformity, the low-temperature melting peak does almost 
not move. This difference from aforementioned melting behavior further confirms the melting-recrystallization mechanism of PLLA/MgPA system.

\subsection{Thermal stability}

Thermal stability is a crucial index in determining the working temperature of polymers [27]. Here, thermal stability of PLLA/MgPA systems was evaluated using TGA. Fig. 8 shows the TGA curves of the primary PLLA and PLLA/MgPA samples at a heating rate of $5^{\circ} \mathrm{C} / \mathrm{min}$ under airflow from $35^{\circ} \mathrm{C}$ to $650{ }^{\circ} \mathrm{C}$. Both the primary PLLA and all PLLA/MgPA samples exhibit only one decomposition stage, indicating that the addition of $\mathrm{MgPA}$ can not change the thermal decomposition profile of the PLLA, which is probably associated with the amount of MgPA in PLLA matrix and the compatibility between PLLA and MgPA. However, the MgPA has significant impact on the onset decomposition temperature $\left(\mathrm{T}_{\mathrm{o}}\right)$ defined by TGA software. For the primary PLLA, PLLA/0.2\%MgPA, PLLA/0.5\%MgPA, PLLA/1\%MgPA, PLLA/2\%MgPA, PLLA/3\%MgPA, PLLA/5\%MgPA, the $\mathrm{T}_{\mathrm{o}}$ are $341.3{ }^{\circ} \mathrm{C}, 317.9^{\circ} \mathrm{C}, 299.4^{\circ} \mathrm{C}, 275.0^{\circ} \mathrm{C}, 258.1^{\circ} \mathrm{C}$, $260.4{ }^{\circ} \mathrm{C}$, and $248.4{ }^{\circ} \mathrm{C}$, respectively. It is very clear from the Fig. 8 that the $\mathrm{T}_{\mathrm{o}}$ of PLLA/MgPA sample depends on the MgPA concentration. Additionally, apart from $\mathrm{MgPA} / 3 \% \mathrm{MgPA}$ sample, the $\mathrm{T}_{\mathrm{o}}$ decreases extremely with addition of MgPA into PLLA matrix, especially for PLLA $/ 5 \% \mathrm{MgPA}$ sample, the $\mathrm{T}_{\mathrm{o}}$ is decreased by $92.9{ }^{\circ} \mathrm{C}$. As a result, the incorporation of MgPA reduces the thermal stability of PLLA, though no effect on the thermal decomposition profile.



Fig. 8. TGA of the primary PLLA and PLLA/MgPA at a heating rate of $5{ }^{\circ} \mathrm{C} / \mathrm{min}$

\subsection{Fluidity and mechanical properties}

The fluidity determines directly the processability of polymers in the extrusion process, and the melt index is used to characterize the fluidity of polymers. Usually, the larger the melt mass flow rate (MFR) is, the better the fluidity is. Fig. 9 shows the effect of MgPA on the MFR of PLLA. It is found from Fig. 9 that the MFR increases with increasing of the MgPA concentration, and the MFR of PLLA/5\%MgPA sample is considerably enhanced up to, at least, 16 times with respect to the primary PLLA, implying that the MgPA can improve significantly the fluidity of the PLLA. In addition, the mechanical properties of semicrystalline polymers are related to the crystallinity [28].

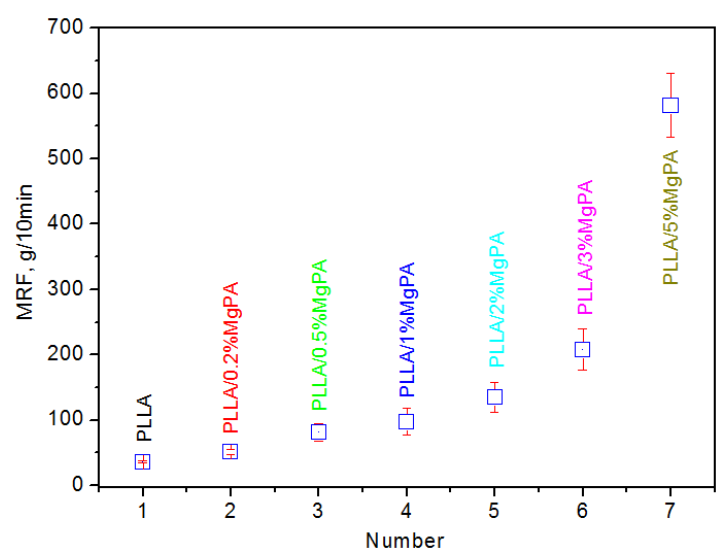

Fig. 9. Effect of MgPA on MFR of PLLA

Here, through aforementioned non-isothermal crystallization analysis, it is a fact that $\mathrm{MgPA}$ can accelerate the crystallization of PLLA. Therefore, the effect of MgPA on the mechanical properties of PLLA was listed in Table.1. Compared to the primary PLLA, the tensile strength of PLLA with various MgPA concentrations from $0.2 \mathrm{wt} . \%$ to $2 \mathrm{wt} \%$ increases, however, when the MgPA concentration exceeds 2 wt.\%, the tensile strength drops dramatically, even the tensile strength of PLLA/5\%MgPA can not be detected. For the elongation at break, the primary PLLA has the largest elongation at break, PLLA/MgPA samples, apart from PLLA/0.2\%MgPA sample, exhibit continuous drop with the increasing of $\mathrm{MgPA}$ concentration, possibly resulting from an increase of crystallinity and inorganic substance from MgPA in PLLA matrix.

Table 1. Mechanical properties of the primary PLLA and PLLA/MgPA samples

\begin{tabular}{|c|c|c|}
\hline Sample & $\begin{array}{c}\text { Tensile strength, } \\
\mathrm{MPa}\end{array}$ & $\begin{array}{c}\text { Elongation at } \\
\text { break, } \%\end{array}$ \\
\hline PLLA & $47.6 \pm 2.4$ & $5.2 \pm 0.6$ \\
\hline PLLA/0.2\%MgPA & $62.3 \pm 1.3$ & $1.0 \pm 0.2$ \\
\hline PLLA/0.5\%MgPA & $64.7 \pm 0.2$ & $1.7 \pm 0.1$ \\
\hline PLLA/1\%MgPA & $65.9 \pm 0.6$ & $1.6 \pm 0.1$ \\
\hline PLLA/2\%MgPA & $62.9 \pm 0.8$ & $1.3 \pm 0.2$ \\
\hline PLLA/3\%MgPA & $41.0 \pm 2.7$ & $0.6 \pm 0.2$ \\
\hline PLLA/5\%MgPA & - & - \\
\hline
\end{tabular}

\section{CONCLUSIONS}

MgPA was prepared to investigate its influence on the non-isothermal crystallization, melting behavior, thermal stability, fluidity and mechanical properties of PLLA using DSC, TGA, melt index instrument, and electronic tensioner. Non-isothermal crystallization results indicated that $\mathrm{MgPA}$ could serve as a nucleating agent to accelerate the crystallization of PLLA, and PLLA/0.5\% MgPA exhibited the largest crystallization rate. Meantime, in nonisothermal crystallization investigation, MgPA concentration, the cooing rate, and the final melting temperature exhibited the distinct effect on the nonisothermal crystallization behavior of PLLA. Melting behavior after isothermal crystallization showed that 
different crystallization temperature and time resulted in the difference of melting behavior, and the double melting peaks of PLLA/MgPA system were attributed to the melting-recrystallization mechanism. And the melting behavior of PLLA/MgPA at different rates after nonisothermal crystallization further confirmed the meltingrecrystallization mechanism. Though the addition of MgPA could not change the thermal decomposition profile of the PLLA, MgPA made the $\mathrm{T}_{\mathrm{o}}$ decrease. Melt index result indicated that the introduction of $\mathrm{MgPA}$ could improve the fluidity of the PLLA. For the influence of MgPA on the mechanical properties of PLLA, the tensile strength of PLLA with MgPA of $0.2 \mathrm{wt} \%$ to $2 \mathrm{wt} . \%$ increased, but the elongation at break dropped with increasing of $\mathrm{MgPA}$ concentration.

\section{Acknowledgments}

This work was supported by National Natural Science Foundation of China (project number 51403027), Natural Science Foundation of Chongqing Municipal Science and Technology Commission (project number cstc2015jcyjBX0123), Scientific and Technological Research Program of Chongqing Municipal Education Commission (project number KJ1601101), Natural Science Foundation of Yongchuan District (project number Ycstc, 2017nc4002), and Innovation Team Project of Chongqing Municipal Education Commission (project number CXTDX201601037).

\section{REFERENCES}

1. Claro, P.I.C.,

Neto, A.R.S.,

Bibbo, A.C.C., Mattoso, L.H.C., Bastos, M.S.R., Marconcini, J.M. Biodegradable Blends with Potential Use in Packaging: A Comparison of PLA/Chitosan and PLA/Cellulose Acetate Films Journal of Polymers and the Environment 24 (4) 2016: pp. $363-371$.

https://doi.org/10.1007/s10924-016-0785-4

2. Marra, A., Silvestre, C., Duraccio, D., Cimmino, S. Polylactic Acid/Zinc Oxide Biocomposite Films for Food Packaging Application International Journal of Biological Macromolecules 88 2016: pp. 254-262. https://doi.org/10.1016/j.ijbiomac.2016.03.039

3. Yuan, J. Polylactic Acid (PLA)/Poly(Butylene Adipate-coterephthalate) (PBAT) Composite Used for. E.g. Disposable Tableware, Comprises PLA, PBAT, Thermoplastic Starch, Two Types of Compatilizer, and Filler, in Weight Ratio of Preset Range, CN103627153-A [P], 2014-03-12.

4. Jandas, P.J., Mohanty, S., Nayak, S.K. Sustainability, Compostability, and Specific Microbial Activity on Agricultural Mulch Films Prepared from Poly(lactic acid) Industrial \& Engineering Chemistry Research 52 (50) 2013: pp. $17714-17724$.

https://doi.org/10.1021/ie4023429

5. Cai, Y.H., Tang, Y., Zhao, L.S. Poly(L-lactic acid) with Organic Nucleating Agent N, N, N'-Tris(1H-benzotriazole) Trimesinic Acid Acethydrazide: Crystallization and Melting Behavior Journal of Applied Polymer Science 132 (32) 2015: pp. 42402-1-42402-7.

https://doi.org/10.1002/app.42402

6. Zhao, R., Li, X., Sun, B.L., Tong, Y., Jiang, Z.Q., Wang, C. Nitrofurazone-loaded Electrospun PLLA/SericinBased Dual-layer Fiber Mats for Wound
Dressing Applications

2015: pp. $16940-16949$.

https://doi.org/10.1039/c4ra16208k

7. Wang, H.L., Liu, H., Chu, C.J., She, Y., Jiang, S.W., Zhai, L.F., Jiang, S.T., Li, X.J. Diffusion and Antibacterial Properties of Nisin-Loaded Chitosan/Poly(L-lactic acid) Towards Development of Active Food Packaging Film Food and Bioprocess Technology 8 (8) 2015: pp. $1657-1667$.

https://doi.org/10.1007/s11947-015-1522-z

8. Cipriano, T.F., da Silva, A.L.N., da Silva, A.H.M.D.F.T., de Sousa, A.M.F., da Silva, G.M., Rocha, M.G. Thermal, Rheological and Morphological Properties of Poly(lactic acid)(PLA) and Talc Composities Polimeros-Ciencia E Tecnologia 24 (3) 2014: pp. 276-282.

https://doi.org/10.4322/polimeros.2014.067

9. Delgado, P.A., Brutman, J.P., Masica, K., Molde, J., Wood, B., Hillmyer, M.A. High Surface Area Carbon Black (BP-2000) As A Reinforcing Agent For Poly[(-)Lactide Journal of Applied Polymer Science 133 (45) 2016: pp. 43926-1 - 43926-9.

https://doi.org/10.1002/app.43926

10. Li, C.L., Dou, Q. Non-isothermal Crystallization Kinetics And Spherulitic Morphology of Nucleated Poly(Lactic Acid): Effect of Dilithium Hexahydrophthalate as a Novel Nucleating Agent Thermochimica Acta 594 2014: pp. $31-38$. https://doi.org/10.1016/j.tca.2014.08.036

11. Wang, Y.M., He, D.R., Wang, X., Cao, W., Li, Q., Shen, C.Y. Crystallization of Poly(Lactic Acid) Enhanced by Phthalhydrazide as Nucleating Agent Polymer Bulletin 70 (10) 2013: pp. 2911-2922. https://doi.org/10.1007/s00289-013-0996-y

12. Li, J., Chen, D.K., Gui, B.Z., Gu, M.H., Ren, J. Crystallization Morphology and Crystallization Kinetics of Poly(Lactic Acid): Effect Of NAminophthalimide as Nucleating Agent Polymer Bulletin 67 (5) 2011: pp. $775-791$. https://doi.org/10.1007/s00289-010-0419-2

13. Fan, Y.Q., Yu, Z.Y., Cai, Y.H., Yan, S.F., Chen, X.S., Yin, J.B. Crystallization Behavior and Crystallite Morphology Controlling of Poly(L-lactic acid) by Adding N, N'-Bis(benzoyl) Sebacic Acid Dihydrazide Polymer International 62 (4) 2013: pp. 647-657. https://doi.org/10.1002/pi.4342

14. Bai, H.W., Huang, C.M., Xiu, H., Zhang, Q., Fu, Q. Enhancing Mechanical Performance of Polylactide by Tailoring Crystal Morphology and Lamellae Orientation with the Aid of Nucleating Agent Polymer 55 2014: pp. 6924-6934. https://doi.org/10.1016/j.polymer.2014.10.059

15. Zou, G.X., Jiao, Q.W., Zhang, X., Zhao, C.X., Li, J.C. Crystallization Behavior and Morphology of Poly(lactic acid) with a Novel Nucleating agent Journal of Applied Polymer Science 132 (5) 2015: pp. 41367-1-41367-8. https://doi.org/10.1002/app.41367

16. Cai, Y.H., Yan, S.F., Yin, J.B., Fan, Y.Q., Chen, X.S. Crystallization Behavior of Biodegradable Poly(L-lactic acid) Filled with a Powerful Nucleating Agent-N, N'Bis(benzoyl) Suberic Acid Dihydrazide Journal of Applied Polymer Science 121 (3) 2011: pp. 1408-1416. https://doi.org/10.1002/app.33633

17. Hua, S., Chen, F., Wang, H.Q., Liu, Z.Y., Yang, W., Yang, M.B. Effect of Cellulosic Graft Copolymer on Crystallization and Extension Rheology 
Properties of Polylactic Acid Acta Polymerica Sinica 8 2016: pp. 1136-1144.

https://doi.org/10.11777/j.issn1000-3304.2016.15376

18. Hua, S., Chen, F., Liu, Z.Y., Yang, W., Yang, M.B. Preparation of Cellulose-Graft-Polylactic Acid Via Melt Copolycondensation for Use in Polylactic Acid Based Composites; Synthesis, Characterization and Properties RSC Advances 6 2016: pp. $1973-1983$. https://doi.org/10.1039/c5ra23182e

19. Li, C.L., Dou, Q. Effect of Metallic Salts of Phenylmalonic Acid on the Crystallization of Poly(L-lactide) Journal of Macromolecular Science Part B: Physics 55 (2) 2016: pp. $128-137$.

https://doi.org/10.1080/00222348.2015.1125050

20. Ye, H.M., Hou, K., Zhou, Q. Improve the Thermal and Mechanical Properties of Poly(L-lactide) by Forming Nanocomposites with Pristine Vermiculite Chinese Journal of Polymer Science 34 (1) 2016: pp. 1-12. https://doi.org/10.1007/s10118-016-1724-5

21. Cai, Y.H., Zhao, L.S., Tang, Y. Thermal Performance of a Blend System Based on Poly(L-lactic acid) and an Aliphatic Multiamide Derivative Derived from 1H-Benzotriazole Journal of Macromolecular Science Part B Physics 56 (1) 2017: pp. $64-73$. https://doi.org/10.1080/00222348.2016.1261594

22. Li, X.X., Yin, J.B., Yu, Z.Y., Yan, S.F., Lu, X.C., Wang, Y.J., Cao, B., Chen, X.S. Isothermal Crystallization Behavior of Poly(L-Lactic Acid)/Organo-Montmorillonite Nanocomposites Polymer Composites 30 (9) 2009: pp. $1338-1344$. https://doi.org/10.1002/pc.20721
23. Zhang, Y.H., Cai, Y.H. A Study on Physical Performance for Poly(L-lactic acid) in Addition of Layered Strontium Phenylphosphonate International Journal of Polymer Science 2016 2016: pp. 3926876-1-3926876-6. https://doi.org/10.1155/2016/3926876

24. Fan, Y.Q., Zhu, J., Yan, S.F., Chen, X.S., Yin, J.B. Nucleating Effect and Crystal Morphology Controlling Based on Binary Phase Behavior Between Organic Nucleating Agent and Poly(L-Lactic Acid) Polymer 67 2015: pp. $63-71$. https://doi.org/10.1016/j.polymer.2015.04.062

25. Cai, Y.H., Zhao, L.S. Thermal Behavior of Modified Poly (L-lactic acid): Effect of Aromatic Multiamides Derivative Based on 1H-benzotriazole E-Polymers 16 (4) 2016: pp. $303-311$. https://doi.org/10.1515/epoly-2016-0052

26. Xin, C.Z., Zhang, H., Wang, Y.W., Yu, X. Study on Multiple Melting Transformation and Cold-Crystallization Behaviors of PLA Plastics Science and Technology 45 (1) 2017: pp. 74-77. (In Chinese)

27. Elsawy, M.A., Saad, G.R., Sayed, A.M. Mechanical, Thermal, and Dielectric Properties of Poly(lactic acid)/Chitosan Nanocomposites Polymer Engineering and Science 56 (9) 2016: pp. 987-994. https://doi.org/10.1002/pen.24328

28. Wu, W.D., Wu, G.F., Zhang, H.X. Effect of Wood Flour as Nucleating Agent on the Isothermal Crystallization of Poly(Lactic Acid) Polymers Advanced Technologies 28 2017: pp. $252-260$. https://doi.org/10.1002/pat.3881 